\title{
What role for fission?
}

\section{Leslie Shepherd assesses the contribution nuclear fission can make to the energy requirements of the next 50 years}

$\mathrm{D}_{\mathrm{c}}^{\mathrm{u}}$ URING the 1960s annual world energy demand was expanding at a rate of $4.5 \%$ a year. If that trend had continued, then 50 years from now the energy demand would be almost ten times as great as at present. With the emphasis that is now being set on the need for more careful and efficient use of energy, however, a lower rate of growth of perhaps $3.5 \%$ a year seems more probable for the future.

On this basis, 50 years from now we should be consuming primary energy at a rate of $1.5 \times 10^{18}$ kilojoules a year and the cumulative consumption in those 50 years would be $3 \times 10^{19}$ kilojoules. It is extremely unlikely that more than two-thirds of this could be met by fossil fuels because of the limitation on the total economic resources of petroleum oil and natural gas $\left(\sim 10^{19}\right.$ kilojoules) and the feasible rate of extraction in the case of solid fuels. In fact, if the mining of coal and lignite were steadily increased by a factor of 5 over the next 50 years, the cumulative energy yield from these would be no more than $10^{19}$ kilojoules.

Nuclear fission, as the only practical alternative energy source to coal and oil on the scale which we are concerned with, therefore, may have to contribute at least one-third of the cumulative consumption by the year 2025 and thereafter provide the bulk of the future demand.

\section{Uranium utilisation}

Since uranium is the only natural source of fissile material, U-235, it is the basic raw material of nuclear power. One tonne of natural uranium contains sufficient U-235 to yield $5 \times 10^{11}$ kilojoules of energy. The OECD's survey listing the reasonably assured and estimated additional resources of uranium from rich ores, published in December 1975, gives a current total of 3.5 million tonnes, the U-235 content of which, on its own, would yield only $1.75 \times 10^{18}$ kilojoules. This is not a very impressive amount of energy-no more, in fact, than the present measured reserves of natural gas would yield.

Fortunately, the real reserves of fission energy, if they are properly exploited, are certain to be orders of magnitude greater than this figure

Dr Shepherd is the former head of the now defunct Dragon High Temperature Reactor Project at Winfrith, Dorset. suggests. This is partly because exploration of uranium resources is still in its early stages and the actual amounts economically extractable are certain to be far greater than indicated in contemporary estimates. In addition, nuclear reactors not only consume the fissile U-235 charged into them, but also generate fresh fissile material by neutron absorption in the so-called fertile isotopes U-238 (which constitutes more than $99 \%$ of natural uranium) and Th-232 (the whole of natural thorium); this process of converting fertile to fissile material enables us to increase the fissionable content of nuclear fuel many fold.

The principal fissile isotopes resulting from these fertile captures are $\mathrm{Pu}-239$ (from U-238) and U-233 (from Th-232). The amount of energy which we are able to derive from the originally mined natural uranium (and thorium) will be determined by the extent to which these secondary fissile isotopes can be generated and utilised starting from the primary U-235. This is a question of the 'neutron economies' of the various possible reactor systems and the fuel cycles adopted in themthe Uranium Cycle involving U-238/ $\mathrm{Pu}-239$, and the Thorium Cycle involving Th-232/U-233.

Not all of the neutrons absorbed in U-233, U-235 and Pu-239 cause fission; a proportion of the neutrons captured produce the higher isotopes U-234, U-236 and Pu-240, which in turn can absorb further neutrons yielding still higher isotopes. In fuels which have been in a reactor for some time the fissile components build up into a chain of isotopes (U-233, U-234, U-235, U-236 in the thorium fuel cycle, and $\mathrm{Pu}-239$, $\mathrm{Pu}-240, \mathrm{Pu}-241, \mathrm{Pu}-242$ in the uranium cycle). All of these isotopes have to be taken into account in evaluating neutron economy.

\section{Neutron economy}

Neutron economy refers to the balance of the processes which produce and absorb neutrons in a nuclear reactor. Each fission is the result of the absorption of a neutron in a fissile nucleus, and in the process fresh neutrons are emitted. One of these is required to produce a further fission, the balance going either into productive or nonproductive processes. The productive process is neutron-absorption in the fertile isotopes, U-238 or Th-232, which yields new fissile material. Nonproductive processes include:
- neutron-capture in the fixed materials making up the reactor core;

- absorption in fission products as they build up and in the control rods which are introduced to maintain the neutron balance as the fuel burns up; - the non-fission neutron capture in the fissile species, which was mentioned above (the ratio of non-fission captures to fission captures is referred to as the $\alpha$-value of the fissile species in question);

- neutron leakage from the reactor core.

It is, of course, the neutron absorption in fertile material, leading to the generation of fresh fissile isotopes, which is important, since it determines the ultimate amount of energy which may be derived from uranium and thorium resources. The ratio of fresh fissile atoms produced to those consumed in the chain of events described is known as the conversion ratio. If this is less than unity the amount of fissile material in the reactor steadily diminishes during operation and loss has to be made up periodically. However, if the ratio is greater than unity (it is then called the breeding ratio), there is a surplus of fissile materials available for other reactors and the system is said to breed.

Neutron economy varies according to the type of reactor and the manner in which it is operated; it also depends on the fuel cycle (uranium or thorium) adopted. The optimum situation is achievable in fast reactors, where breeding is possible largely because of the relatively low $\alpha$-values in all the fissile materials when the neutron energy is high.

The uranium cycle is better than the thorium cycle in fast systems. This is because of the greater yield of neutrons in the fission of $\mathrm{Pu}-239$ as compared with U-233, and because the most energetic neutrons can cause direct fission of the fertile U-238 (an effect which is far less pronounced in Th-232) and, by this means, boost significantly the number of available neutrons. In thermal reactors, the $\alpha$-value is very high for Pu-239 $(\sim 0.6)$ and low in the case of U-233 $(\sim 0.1)$ with the result that much higher conversion ratios are possible with a thorium fuel cycle than with a uranium fuel cycle.

Thus from the standpoint of achieving the maximum energy output from natural uranium resources there is an incentive to develop fast reactors with the uranium cycle and to use the thorium fuel cycle in thermal reactors.

\section{Thermal reactor characteristics}

In a global context three categories of thermal reactor are of interest: light water reactors (LWR), heavy water reactors (HWR) and the helium-cooled 
high temperature reactor (HTR).

As far as neutron loss in the moderator is concerned, light water is worst, carbon is intermediate, while heavy water is essentially non-absorbing. The same remarks apply to light and heavy water as coolants; no neutrons would be absorbed in a helium coolant. L.WR and HWR cores both incorporate a large amount of neutron absorbing metal in fuel element cladding and pressure tubes, so that these systems are appreciably worse in this respect than the HTR which includes no metal structure. Taking these factors into account both the HTR and the HWR have an advantage over the LWR.

The proportion of neutrons lost by absorption in fission products (more or less independent of reactor type) depends upon the extent to which these are allowed to build up relative to the core inventory of fissile material, that is to say the degree of fuel burn-up before it is discharged from the reactor for reprocessing. Reprocessing separates out the fission products from the unburned fissile material which can then be recycled in the reactor. Reprocessing is an expensive matter and for that reason among others it is desirable to keep a high inventory of fissile material in the reactor core (if a good neutron economy is desired) to avoid too frequent recycling.

The yardstick in the evaluation of future thermal reactors is the current uranium fuel cycle LWRs. These operate at present with no recycle. The conversion ratio in the single fuel cycle is about 0.60 , and more than half of the $\mathrm{Pu}-239$ produced is actually consumed in this cycle. An LWR of 1000 MW gross capacity, operated in this way for 30 years at $80 \%$ load factor, would require 6,000 tonnes of natural uranium. At this rate about 25 million tonnes of uranium would be required to yield the $10^{19}$ kilojoules indicated above as a cumulative energy target over the next 50 years. 'This amount could be reduced by about $40 \%$ if fuel were recycled to use up all residual U-235 and plutonium.

Both the HWR and the HTR would achieve a better performance than the LWR with the uranium fuel cycle for the reasons already given. In the case of the HTR, the superior thermodynamic efficiency of the power conversion cycle*, arising from the higher temperatures achieved, would also mean that the useful energy ultimately derived would be substantially higher than with the water cooled reactors.

The biggest gain, however, would come from the use of the thorium fuel cycle in thermal reactors because of

*An electricity generating HWR would have thermal efficiency of $30 \%$ compared with $40 \%$ for a steam cycle HTR and $45-50 \%$ for a hinary cycle HTR. the greater yield of neutrons from U-233 compared with Pu-239. This would carry a potential advantage of about 0.4 in conversion ratio compared with the uranium cycle I.WR and even introduce the possibility of operating thermal reactors as breeders. Howcver, this would require very large inventories of fissile material in these reactors so that the initial large requirement of mined uranium would offset the advantage of the breeding for a very long period, certainly longer than the 50 years considered here.

Furthermore, U-235 being the only naturally occurring fissile material, all nuclear fuel cycles must begin with this isotope. This means that there is an initial phase in which the neutron economy is determined partially by the characteristics of U-235, with a consequently lower conversion ratio during that phase.

High conversion thorium fuel cycle thermal reactors would require some 5-7 million tonnes of uranium to be mined over the next 50 years in order to achieve an energy output of $10^{19}$ kilojoules. This is in excess of the presently estimated resources of uranium from high grade ores. Without doubt, the present figures greatly underestimate the actual available resources, particularly if one takes into account the acceptability of using much more costly uranium in high conversion or breeding systems.

At the end of that time, however, at the $3.5 \%$-a-year rate of energy growth the annual nuclear energy demand would be $\sim 10^{18}$ kilojoules and would be increasing. It is difficult to envisage meeting this requirement without having built up an adequate breeder reactor capacity. This provides the incentive to develop a technically and economically viable fast reactor and to have such a system established on a substantial scale 50 years from now.

\section{Fast reactor exploitation}

A fast reactor using plutonium will have an initial induction phase in going from U-235 to Pu-239, as would be the case in building up a U-233 inventory in a thermal reactor. Currently, the accepted strategy is to use thermal reactors (predominantly LWRs) to produce the necessary plutonium inventories for fast breeders. Unfortunately, this is a particularly inefficient process, a non-recycle LWR yielding only about a quarter of a kilogramme of fissile plutonium per MW-year.

Taking four tonnes as being a minimum plutonium inventory for a sodium-cooled fast breeder of 1000 MW capacity (2.5 tonnes in the core and 1.5 tonnes in recycle), its production would require an LWR of corresponding power output to operate for 20 years at $80 \%$ load factor, consuming more than 3,000 tonnes of uranium in the process.

Subsequently, the fast reactor would yield excess plutonium which would be available to build up further inventories. There is a possibility, however, that the doubling time - that is to say the time for the fast reactor to generate sufficient excess plutonium to provide a further reactor inventory-may be very long, which would make for an excessively slow build-up in the ratio of fast reactors to LWRs.

In such circumstances there would be, certainly over the next 50 years, an unacceptably high preponderance of

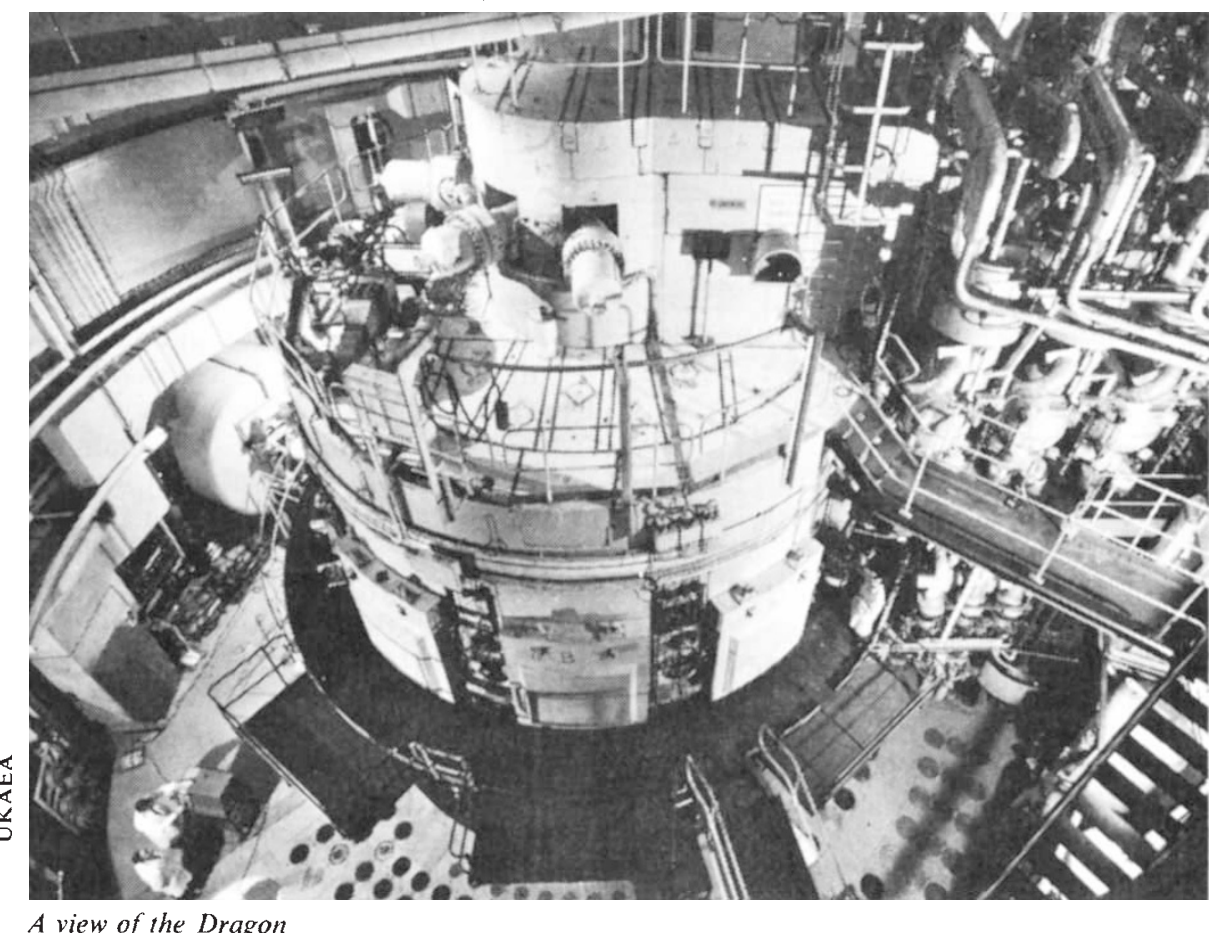

$A$ view of the Dragon 
LWRs over FBRs, so that one would be far removed from an overall breeding situation and the total uranium demand could be significantly higher than for a programme based only upon high-conversion thorium fuel cycle reactors.

This approach is unnecessary, however, it being much more logical to start fast reactors with U-235 and produce the eventual $\mathrm{Pu}-239$ inventory in situ. In this way all of the plutonium would be produced and consumed in its most favourable environment. The time to produce a full plutonium inventory and, therefore, a true breeding situation would be much shorter and the uranium input very much reduced, possibly by a factor of four, compared with the LWR approach.

A further advantage of this course is that it would make the fast reactor independent of any thermal system, and it would relieve the latter of the requirement to work on the uranium fuel cycle in order to provide plutonium for fast systems.

While thermal reactors are not appropriate sources of plutonium for fast reactors, it is worth stressing that the converse is not true, insofar as U-233 could be generated efficiently in thorium introduced into the blanket of a fast breeder reactor. In this way a fast reactor with a good breeding ratio could support high conversion thermal reactors with a combined energy output several times greater than its own.

This is an important possibility leading to a symbiosis of a small number of fast breeders with a larger number of high conversion helium-cooled high temperature reactors, which would be preferred to the fast reactor on all counts other than neutron economy.

\section{Conclusion}

In the foregoing a world viewpoint has been taken deliberately, because no individual nation can hope to proceed in an isolated manner in resolving problems of such significance as those presented by the energy situation.

Unless some viable major alternative energy source (such as nuclear fusion) comes along, there will be a minimum cumulative requirement of $10^{19}$ kilo- joules of thermal energy from nuclear fission over the next 50 years, and at the end of that time the annual energy contribution will need to be $10^{18}$ kilojoules a year. The requirement is far beyond the capabilities of light water reactors working on their present uranium fuel cycles, but it would not be beyond the capacity of thorium fuel cycle thermal reactors, notably the high temperature reactor, provided that they were being followed up with a well established programme of fast reactors.

However, the strategy of using thermal reactors (predominantly LWRs) to produce the plutonium inventories needed for breeding does not appear to be viable. The rapid exploitation of the breeding capabilities of fast reactors requires that they should generate their own plutonium from the initially available U-235. On this basis the evolution of fast reactor exploitation would proceed independently of the programme of thermal reactors. Eventually, the two would come together in a symbiosis, in which an overall breeding situation would be maintained with a minimum of fast reactors.

\section{FRANCE}

\section{Debating nuclear power}

Alexander Dorozynski reports from France on the nuclear power debate there

THIS year may be decisive for the ambitious French programme of rapid development of nuclear energy. Well before the debate triggered by the "all nuclear" decision of the Pierre Messmer government in March 1974 physicists and ecologists started voicing worries about the programme's safety and reliability, and the doubters appear still to be growing in numbers and in political weight.

The controversy has spread beyond the potential dangers of a technology that has not been entirely mastered. Those arguments find a focus in the huge nuclear waste treatment plant in La Hague, at the tip of the Cotentin directly south of Bournemouth, and in the Superphénix fast breeder reactor, to be located just $44 \mathrm{~km}$ from Lyon. The debate now extends to many of the economic and political arguments advanced by the powerful Electricité de France (EDF), the state monopoly employing some 100,000 persons and one of France's largest and most powerful enterprises.

The Ministry of Industry and Research has been only marginally effective in dealing with the 'dissidents', and in the face of mounting public awareness, a public relation campaign is being mounted by EDF. Embarrassingly, some of the approaches to be taken have been revealed by an ecological weekly, La Gueule Ouverte, which has published a confidential EDF document giving recommendations about how to deal with different categories of opponents, such as the public at large, members of the parliament, physicians, teachers, journalists, and so on.

Now another publication, Science et $V i e$, France's largest science magazine, is publishing the results of a debate it has organised about the economic soundness of the programme. The debate put face to face economists from the EDF and members of the Institut Economique et Juridique de l'Energie (IEJE), a small group formed at the University of Social Sciences of Grenoble. A guest participant was Professor Irvin C. Bupp, Jr, a Harvard University economist who has taken part in a MIT study of the evolution of the price of water reactors in the US -PWRs are being installed in France under a patent agreement with Westinghouse.

The initial nuclear programme has already been toned down under Valery Giscard d'Estaing's presidency : annual plant construction will be decreased from a $6,000 \mathrm{MW}$ capacity in 1976 and 1977 to $5,000 \mathrm{MW}$ in 1978 , and the goal of producing by 1985 nuclear energy equivalent to 60 million tons of oil has been adjusted downward to 55 million. But until now, few had challenged the figures authoritatively produced by EDF concerning the price of the nuclear kilowatt, and the cost of nuclear plants.

"The only economists who have ventured to challenge official figures are those of the IEJE," points out one narticipant, Jean Marie Chevalier, professor of economics at the University of Paris-Dauphine. "In fact, the nuclear programme has been imposed upon the country by EDF and the Commissariat a l'Energie Atomique (CEA). Never has there been the slightest counterexpertise. The government let it go without compromising itself. Thus, if need be, it will be able to reject upon EDF the responsibility of the aberrant situation we might end up with." The figures are now likely to be subjected to close scrutiny.

For instance, EDF economists have tagged the nuclear KWh with a cost of 7.5 centimes, while that of the 'classical', oil-fired KWh varies between 11.5 and 12.5 centimes. IEJE economists ask if this price is realistic. Just across the border, in West Germany, the nuclear KWh is priced at 6 pfennig (12 centimes), and Patrice Romain of the IEJE maintains 